\title{
Analyzing Pedestrian Fatality Risk in Accidents at Mid-Blocks
}

\author{
Yanyan Chen, Jiajie Ma, Ning Chen \\ College of Metropolitan Transportation, Beijing University of Technology, Beijing, China \\ Email: 825768581@qq.com
}

How to cite this paper: Chen, Y.Y., Ma, J.J. and Chen, N. (2019) Analyzing Pedestrian Fatality Risk in Accidents at Mid-Blocks. Journal of Transportation Technologies, 9 , 171-192.

https://doi.org/10.4236/jtts.2019.92011

Received: January 12, 2019

Accepted: April 5, 2019

Published: April 8, 2019

Copyright $\odot 2019$ by author(s) and Scientific Research Publishing Inc. This work is licensed under the Creative Commons Attribution International License (CC BY 4.0).

http://creativecommons.org/licenses/by/4.0/

\begin{abstract}
Objective: Pedestrian safety is considered as one of the greatest concerns, especially for developing countries. In the year of 2015 , about $48 \%$ pedestrian accidents with $56 \%$ fatalities occurred at mid-blocks in Beijing. Since the high frequency and fatality risk, this study focused on pedestrian accidents taking place at mid-blocks and aimed at identifying significant factors. Methods: Based on total 10,948 crash records, a binary logit model was established to explore the impact of various factors on the probability of pedestrian's death. Furthermore, first-degree interaction effects were introduced into the basic model. The Hosmer-Lemeshow goodness-of-fit test was used to assess the model performance. Odds ratio was calculated for categorical variables to compare significant accident conditions with the conference level. Variables within consideration in this study included weather, area type, road type, speed limit, pedestrian location, lighting condition, vehicle type, pedestrian gender and pedestrian age. Results: The calibration results of the model show that the increased fatality chances of an accident at mid-blocks are associated with normal weather, rural area, two-way divided road, crossing elsewhere in carriageway, darkness (especially for no street lighting), light vehicle, large vehicle and male pedestrian. With road speed limit increasing by $10 \mathrm{~km} / \mathrm{h}$, the probability of death accordingly increases by $46 \%$. Older victims have higher chances of being killed in a crash. Moreover, three interaction effects are found significant: rural area and two-way divided, rural area and crossing elsewhere as well as speed limit and pedestrian age. Conclusions: This study has analyzed police accident data and identified factors significant to the death probability of pedestrians in accidents occurred at mid-blocks. Recommendations and improving measures were proposed correspondingly. Behaviors of different road users at mid-blocks should be taken into account in the future research.
\end{abstract}

\section{Keywords}

Pedestrian Accident, Mid-Block, Fatality Risk, Logistic Regression 


\section{Introduction}

Pedestrians are regarded as one of the most vulnerable victims among all road accidents. Without any protection (e.g. vehicle body, helmets), they get hurt directly and have higher chances of severe injury or even death in a traffic accident. Once pedestrians get involved in a crash, the probability of resulting in a fatal outcome is 3.7 times higher [1]. In 2016, 5987 pedestrians were killed in the United States, making up 16\% of total road fatalities [2]. Meanwhile, there were $21 \%$ of total 25,600 fatalities in 2016 across the Europe [3]. On a worldwide scale, over 400,000 pedestrians are killed every year in road crashes [4]. Considering this serious problem, many international organizations, such as the United Nations (UN), World Health Organization (WHO) and European Union (EU), have been proceeding the road safety programs and campaigns continuously.

In particular, pedestrians are confronting with more danger in developing countries. As the World Bank reported, approximately $70 \%$ of traffic-related fatalities occur in developing countries across the world, in which $65 \%$ involve pedestrians [5]. China, as one of the biggest developing countries, has developed rapidly over past decades, and became the second largest economy in 2010 . Along with China's remarkable achievements, there are many problems left in the meantime, one of which is the huge amount of road accidents and fatalities. In 2013, China had 45,367 vehicle-pedestrian crashes, in which 15,171 involved fatalities, accounting for 33\% [6]. Since pedestrian safety issue raised a great concern nationwide, a series of programs and projects were sponsored by the government. This challenge has been taken up by the Public Safety Risk Prevention and Emergency Technical Equipment (PSRPETE) research project, which belongs to the National Key Research and Development Program of China.

This paper aims at finding and comparing factors contributing to the high fatality in pedestrian accidents occurring at mid-blocks. Taking the city of Beijing as the study area, characteristics of vehicle-pedestrian crashes are thoroughly analyzed in the study. As we know, Beijing is the capital city of China, and one of cosmopolitan cities in the whole world. What Beijing is going through will become a reality for some other developing cities in the future. Thus, it is valuable to pay close attention to historical traffic accident data, provided by Beijing Traffic Management Bureau (BTMB). In practice, "accidents" can be defined as injury crashes, which involve one person killed or injured at least. In order to identify factors leading to the highest death risk, distributions of killed victims by weather, area type, road type, lighting condition, vehicle type, pedestrian location and demographic characteristics in Beijing are examined. A logistic regression model is developed to evaluate the impact of different factors on pedestrian fatality risk, which is defined as the probability of a pedestrian getting killed in an accident. Specifically, fatality risk is not the same as the crash risk or accident risk. If we would like to calculate the crash risk, some other data are needed, like the volumes of vehicle and pedestrian at each accident spot. Gener- 
ally, these data are just not available.

From existing literature, we find that many methods are proposed to model and analyze pedestrian accidents, and they can be concluded as three main approaches as follows:

- Accident frequency modeling and statistical analysis [7] [8] [9] [10] [11].

- Spatial and temporal analysis of accident distribution [12]-[17].

- Fatality risk and injury severity modeling [18]-[32].

This study uses the last approach to analyze the pedestrian accidents. International literature reported above shows that the impact of various factors on the severity of vehicle-pedestrian crashes has been investigated by some researchers. These factors can be classified as four facets: characteristics of pedestrian and driver, vehicle attributes, road features, and environmental conditions [33]. The common findings from existing studies present that the injury severity of pedestrians in a crash was raised by factors that mainly include aged pedestrians, heavy vehicles, roads with higher speed limit, and worse lighting conditions.

Although studies mentioned before focused less on mid-blocks, there are still a lot of helpful insights into the causation of vehicle-pedestrian crashes shown in their findings. Based on comprehensive traffic crash information of Hong Kong, Sze and Wong (2007) demonstrated factors that led to a higher risk of mortality and severe injury were old casualty (above 65 years), head injury, within $15 \mathrm{~m}$ of a crosswalk, speed limit above $50 \mathrm{~km} / \mathrm{h}$, signalized intersection and more than two lanes [20]. Through pedestrian crash data from New York and Montreal, Mohamed et al. (2013) found that pedestrian age, location type, driver age, vehicle type, driver alcohol involvement, lighting conditions, and several built environment characteristics influenced the likelihood of fatal accidents [24]. Sasidharan and Menéndez (2014) used datasets from Switzerland and their results showed that pedestrian age and gender, dark unlighted mid-blocks and road sections were significantly associated with higher odds of pedestrian fatality [25]. A study of pedestrian accidents in the USA concluded that older pedestrians (over 65 years old), pedestrians not wearing contrasting clothing, adult drivers (16 24), drunk drivers, time of day (20:00 - 5:00), divided highways, multi-lane highways, darkness, and heavy vehicles were associated with severe injuries [28]. In the meantime, they also concluded that crossing the street at crosswalks, urban areas, and presence of traffic control devices (signal and sign) decreased the probability of severe injuries. Kim et al. (2017) analyzed three-year pedestrian crash data and found that factors associated with increased severity of pedestrian injury included intoxicated drivers, road-crossing pedestrians, elderly pedestrians, heavy vehicles, wide roads, darkness, and fog [30].

There are also studies mainly focusing on pedestrian crashes that occurred at intersections. Lee and Abdel-Aty (2005) analyzed four-year vehicle-pedestrian accidents at intersection in Florida [10]. They demonstrated that the group of drivers and pedestrians, and environmental conditions are associated with high pedestrian crashes through log-linear models. Haleem et al. (2015) analyzed pe- 
destrian injury severity in crashes that occurred at signalized and unsignalized intersections [26]. At signalized locations, higher AADT, speed limit, percentage of trucks, old pedestrians, at-fault pedestrians, rainy weather, and dark lighting condition increased the pedestrian severity risk. Except for variables mentioned above, pedestrian walking along the roadway and vans were also associated with higher pedestrian severity risk at unsignalized intersections. Based on two-year crash records at intersections in Cook County, Illinois of the US, Ma et al. (2017) employed an ordered probit model to identify factors significant to pedestrian injury severity for young, middle-aged and older driver groups [29]. Through the driving reliability and error analysis method, Xie et al. (2018) provided an in-depth analysis of 28 fatal pedestrian crashes [31]. The results showed that key issues affecting pedestrian safety at intersections can be categorized as four aspects: deficient safety infrastructure, lack of pedestrian education, inadequate driver training and insufficient traffic law enforcement.

However, unlike other studies, Zahabi et al. (2011) estimated various factors that potentially have an effect on the pedestrian's injury severity, and they found that road speed limit had little significant relation with injury levels [34]. Islam and Jones (2014) analyzed pedestrian injury severity for pedestrian at-fault crashes in Alabama [35]. The results of their study showed that some factors are only significant in one location (urban or rural). They also found that dark lighting conditions, two-lane roadways, and pedestrians younger than 12 would increase pedestrian injury severity regardless of the location of the crash.

In summary, researchers have investigated pedestrian accidents mostly on a whole scale of road networks or at interactions, and a number of factors affecting the severity of pedestrians were uncovered. However, there were limited studies specifically focusing on the vehicle-pedestrian accidents occurred at mid-blocks. Since mid-blocks have greatly discrepancies on geometry and road facilities from intersections or any other road sections, studying pedestrian crashes at mid-blocks would provide meaningful insights to the road designing and improve the safety of those vulnerable road users. In addition, pedestrians have various behaviors when moving at mid-blocks, which may also be worth taking a view.

In terms of the lack of thorough investigation on the vehicle-pedestrian accidents occurred at mid-blocks, this paper used one-year police accident data of Beijing to explore deeper causes of fatal accident outcomes. A binary logistic regression model was established, and various factors impacting the fatality risk of pedestrians were estimated. Besides, comparisons between first-degree interaction effects of factors were made, which was often neglected by former studies. Based on the results, we found several factors that are critical for the accident severity, and potential explanations are reasoned properly. Recommendations and suggestions from different perspectives were proposed for decision makers, which can contribute to improve the road safety and decrease the death rate of pedestrians at mid-blocks. 


\begin{tabular}{cc}
\hline Nomenclature & \\
\hline$P_{n}$ & Probability of death for pedestrian n \\
$X_{n}$ & Independent variable for pedestrian $\mathrm{n}$ \\
$\beta$ & Corresponding efficient for variable $X_{n}$ \\
$K$ & Number of independent variables \\
$M$ & Number of variables and interaction effects \\
$H L$ & Hosmer-Lemeshow statistic \\
$O$ & Observed accidents of a fatal outcome \\
$E$ & Expected accidents of a fatal outcome \\
$N$ & Number of observations \\
$\theta_{i}$ & Predicted risk for the $i^{\text {th }}$ risk decile group \\
\hline
\end{tabular}

\section{Methods}

\subsection{Model Specification}

A study on injury severity is helpful for identifying risk factors of increasing the death rate of vehicle-pedestrian accidents. Eluru et al. (2008) and Ma et al. (2017) have comprehensively concluded that many researchers have tried to analyze the injury severity through statistical models, like multinomial logit, ordered probit and so forth [29] [36]. Binary logistic regression has also been used to establish models of fatality risk in studies [5] [32]. The Beijing accident dataset classifies the injury severity into fatal, severe and light. However, it should be mentioned that the criterion of injury severity among different countries is not identical. For that reason, it is decided to use binary classification (fatal and not fatal) to compare and analyze the result. Logistic regression is useful when you are predicting a binary outcome from a set of continuous and/or categorical predictor variables. Consequently, the binary logit model is supposed to be the most appropriate method to examine each variable in this study.

According to the outcome for each accident, fatality risk is defined: fatal or not fatal (injury). A binary logistic regression model can be used to express the pedestrian's death probability. A fatal accident outcome is represented by the value of 1 , and other consequences are represented by 0 . Considering the outcome is dichotomous, the probability $\left(P_{n}\right)$ of death for pedestrian $n$ can be determined by:

$$
P_{n}=\frac{\mathrm{e}^{f\left(X_{n}\right)}}{1+\mathrm{e}^{f\left(X_{n}\right)}}=\frac{1}{1+\mathrm{e}^{-f\left(X_{n}\right)}},
$$

where $P_{n}$ is the probability of being killed for pedestrian $n ; f\left(X_{n}\right)$ is a linear function of the explanatory variables.

In the logistic regression model, this linear function is related to the expected value of the response, which is composed by $K$ independent variables and coefficients:

$$
f\left(X_{n}\right)=\beta_{0}+\beta_{1} X_{1 n}+\beta_{2} X_{2 n}+\cdots+\beta_{j} X_{j n}+\cdots+\beta_{K} X_{K n},
$$


where $X_{\text {in }}$ is the $f^{\text {th }}$ vector of independent variables for pedestrian $n$, with $\beta$ as the corresponding coefficient.

When there are two or more independent variables in the experimental study, the effect of one of the independent variables is inconsistent at each level of the other independent variable. This phenomenon is called interaction effects. In this study, we mainly focused on the first-degree interaction effects, which are only between two explanatory variables. Therefore, function $f\left(X_{n}\right)$ can be formulated by the following expression:

$$
f\left(X_{n}\right)=\beta_{0}+\beta_{1} X_{1 n}+\beta_{2} X_{2 n}+\cdots+\beta_{K} X_{K n}+\beta_{K+1} X_{1 n} X_{2 n}+\cdots+\beta_{M} X_{K n} X_{(K-1) n},
$$

where $K$ is the number of independent variables; $M$ is the number of variables and interaction effects, $M=K(K+1) / 2$.

\subsection{Goodness-of-Fit Test}

Goodness-of-fit tests are calculated in order to decide whether the logistic regression model is correctly specified. If the p-value is above 0.05 , then the model passes the test. In consideration of our model containing both categorical and continuous variables, Hosmer-Lemeshow test can be used to examine whether the model is consistent with data. The formula of Hosmer-Lemeshow test can be expressed as:

$$
H L=\sum_{i=1}^{G}\left(\frac{\left(O_{i}-E_{i}\right)^{2}}{N_{i} \theta_{i}\left(1-\theta_{i}\right)}\right),
$$

where $H L$ is the Hosmer-Lemeshow statistic; $O_{i}$ is the observed accidents of a fatal outcome; $E_{i}$ is the expected accidents of a fatal outcome; $N_{i}$ is the number of observations; $\theta_{i}$ is the predicted risk for the $I^{\text {th }}$ risk decile group, and $G$ is the number of groups. The test statistic asymptotically follows a $\chi^{2}$ distribution ( $G-$ 2) degrees of freedom. To help avoid singular decile groups, the number of risk groups may be fine-tuned depending on how many fitted risks are identified by the model.

\subsection{Odds Ratio}

In the logistic regression model, coefficients of categorical variables at statistically significant levels can be used to calculate the odds ratio (OR) of fatality under some situations. OR is given by the formula:

$$
O R\left(X_{i}\right)=\exp \left(\beta_{i}\right) \text {, }
$$

Odds ratio can represent the relative death risk of pedestrians in an accident when some condition occurs comparing with when it does not occur. In the study, we compare different accident conditions with the control level.

\subsection{Data Description}

In this paper, traffic accident data in the whole year of 2015 from Beijing Traffic 
Management Bureau are used for modeling. The number of accidents of vehicle hitting pedestrian in Beijing was 23,378. These accidents occurred mostly at three places: mid-blocks, intersections and roundabouts, and their proportions are presented in Figure 1(a). Among all vehicle-pedestrian accidents, those occurred at mid-blocks account for $48 \%$, which was equivalent to percentage of accidents occurred at intersections, with only $4 \%$ of accidents occurred at roundabouts. However, Figure 1(b) shows that fatal accidents occurred at mid-blocks were more than half (56\%), and the percentage of fatal accidents occurred at intersections decreased to $41 \%$, with the portion of roundabout accidents changing slightly. It can be concluded that vehicle-pedestrian accidents that occur at mid-blocks are more likely to have a fatal outcome. In later sections, this issue will be thoroughly analyzed, and several underlying causes will be excavated.

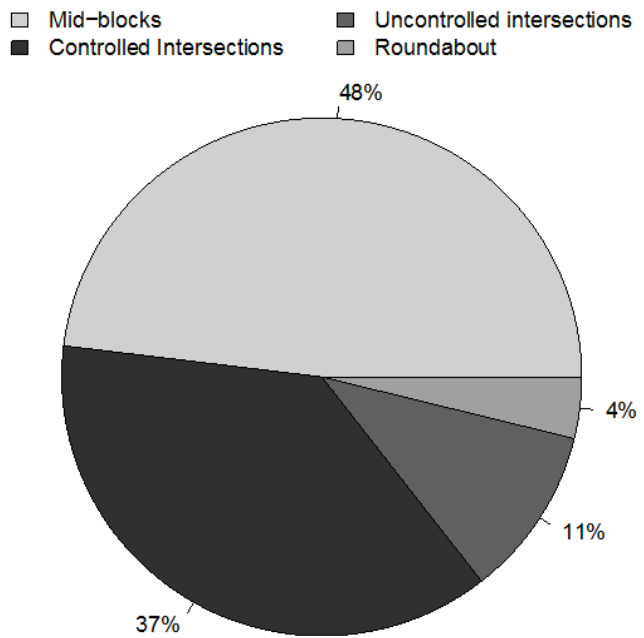

(a) Percentage of total accidents occurred at different locations

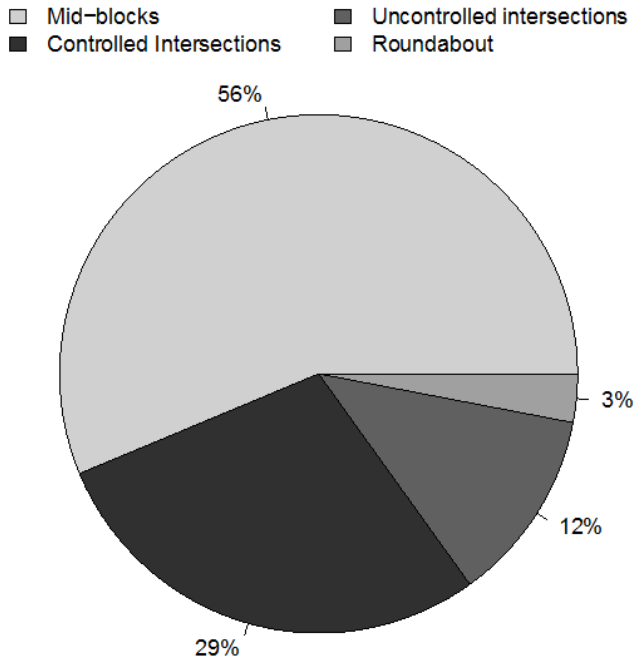

(b) Percentage of fatal accidents occurred at different locations

Figure 1. Percentage of vehicle-pedestrian accidents occurred at different locations. 
The intention of this study is to identify risk factors leading to a higher death rate of pedestrians. After preliminary analysis, potential explanatory variables selected from the dataset are listed as follows:

- weather (normal, adverse)

- area type (urban, rural)

- road type (one-way, two-way undivided, divided)

- road speed limit (continuous: $\mathrm{km} / \mathrm{h}$ )

- pedestrian location (roadside, pedestrian crossing, crossing elsewhere)

- lighting condition (daylight, dark no lighting, dark street lights, dusk or dawn)

- vehicle type (motorcycle, car, light vehicle, heavy vehicle)

- pedestrian gender (male, female)

- pedestrian age (continuous: years)

Levels of each variable are given in parenthesis and the reference level is underlined. Road speed limit and pedestrian age are two continuous variables, and several dummy variables are also defined for categorical variables. In each case, the number of dummy variables should be one less than the number of levels (subtracting reference level).

\section{Results and Discussion}

\subsection{Descriptive Statistics}

After data manipulation, 10,948 reported vehicle-pedestrian accidents occurred at mid-blocks. The distributions of these accidents as well as pedestrians killed and injured are shown in Table 1, according to several characteristics including weather, area type, road type, lighting conditions, vehicle type, and pedestrian location. By calculating the number of fatalities per 100 accidents, we can define the accident severity in the last column of Table 1. It can be found that the importance of these factors seems different from two perspectives: frequency and severity. For example, a large number of accidents (80.8\%) occurred at urban areas while fatalities only comprising $45.2 \%$. The accident severity of the urban area is only 3.1, about one-fifth of the rural area. Mid-blocks on divided two-way roads also seem to be a concern: $10.5 \%$ of accidents occurred there sharing $41.7 \%$ of fatalities, with accident severity being equal to 21.7 .

As for the vehicle type, almost $81.0 \%$ of accidents and $65.8 \%$ of fatalities occurred between cars and pedestrians. Accidents severity is 8.9 killed per 100 hundred for light vehicles, and 14.8 for heavy vehicles. Table 1 also shows that $64.9 \%$ of accidents were located at carriageways resulting in $80.2 \%$ of killed victims (accident severity is 6.8). It should be noted that pedestrians at mid-blocks have larger possibility getting injured or killed when they are crossing elsewhere in carriageways. In fact, the number of pedestrian crossing facilities in Beijing cannot keep the pace of road extensions in newly built-up areas, and additionally traffic schemes changed a lot. 
Table 1. Traffic accidents at mid-blocks in Beijing (2015).

\begin{tabular}{|c|c|c|c|c|c|c|c|c|}
\hline \multirow[t]{2}{*}{ Characteristic } & \multirow[t]{2}{*}{ Category } & \multicolumn{2}{|c|}{ Number of accidents } & \multicolumn{2}{|c|}{ Pedestrian killed } & \multicolumn{2}{|c|}{ Pedestrian injured } & \multirow[t]{2}{*}{ Severity } \\
\hline & & Number & Percent & Number & Percent & Number & Percent & \\
\hline \multirow{3}{*}{ Weather } & Normal & 9698 & $88.6 \%$ & 542 & $90.3 \%$ & 9460 & $88.5 \%$ & 5.6 \\
\hline & Adverse & 1250 & $11.4 \%$ & 58 & $9.7 \%$ & 1234 & $11.5 \%$ & 4.6 \\
\hline & Total & 10,948 & $100.0 \%$ & 600 & $100.0 \%$ & 10,694 & $100.0 \%$ & 5.5 \\
\hline \multirow{3}{*}{ Area type } & Urban & 8847 & $80.8 \%$ & 271 & $45.2 \%$ & 8858 & $82.8 \%$ & 3.1 \\
\hline & Rural & 2101 & $19.2 \%$ & 329 & $54.8 \%$ & 1836 & $17.2 \%$ & 15.7 \\
\hline & Total & 10,948 & $100.0 \%$ & 600 & $100.0 \%$ & 10,694 & $100.0 \%$ & 5.5 \\
\hline \multirow{4}{*}{ Road type } & Divided & 1151 & $10.5 \%$ & 250 & $41.7 \%$ & 930 & $8.7 \%$ & 21.7 \\
\hline & Undivided two way & 9143 & $83.5 \%$ & 326 & $54.3 \%$ & 9083 & $84.9 \%$ & 3.6 \\
\hline & Undivided one way & 654 & $6.0 \%$ & 24 & $4.0 \%$ & 681 & $6.4 \%$ & 3.7 \\
\hline & Total & 10,948 & $100.0 \%$ & 600 & $100.0 \%$ & 10,694 & $100.0 \%$ & 5.5 \\
\hline \multirow{5}{*}{ Lighting conditions } & Daylight & 7871 & $71.9 \%$ & 228 & $38.0 \%$ & 7878 & $73.7 \%$ & 2.9 \\
\hline & Dark no lighting & 440 & $4.0 \%$ & 171 & $28.5 \%$ & 282 & $2.6 \%$ & 38.9 \\
\hline & Dark street lights & 2404 & $22.0 \%$ & 170 & $28.3 \%$ & 2328 & $21.8 \%$ & 7.1 \\
\hline & Dusk or down & 233 & $2.1 \%$ & 31 & $5.2 \%$ & 206 & $1.9 \%$ & 13.3 \\
\hline & Total & 10,948 & $100.0 \%$ & 600 & $100.0 \%$ & 10,694 & $100.0 \%$ & 5.5 \\
\hline \multirow{5}{*}{ Vehicle type } & Motorcycle & 459 & $4.2 \%$ & 13 & $2.2 \%$ & 461 & $4.3 \%$ & 2.8 \\
\hline & Car & 8869 & $81.0 \%$ & 395 & $65.8 \%$ & 8773 & $82.0 \%$ & 4.5 \\
\hline & Light vehicle & 818 & $7.5 \%$ & 73 & $12.2 \%$ & 764 & $7.1 \%$ & 8.9 \\
\hline & Heavy vehicle & 802 & $7.3 \%$ & 119 & $19.8 \%$ & 696 & $6.5 \%$ & 14.8 \\
\hline & Total & 10,948 & $100.0 \%$ & 600 & $100.0 \%$ & 10,694 & $100.0 \%$ & 5.5 \\
\hline \multirow{4}{*}{ Pedestrian location } & Roadside & 2866 & $26.2 \%$ & 101 & $16.8 \%$ & 2904 & $27.2 \%$ & 3.5 \\
\hline & Pedestrian crossing & 977 & $8.9 \%$ & 18 & $3.0 \%$ & 998 & $9.3 \%$ & 1.8 \\
\hline & Crosswalk & 7105 & $64.9 \%$ & 481 & $80.2 \%$ & 6792 & $63.5 \%$ & 6.8 \\
\hline & Total & 10,948 & $100.0 \%$ & 600 & $100.0 \%$ & 10,694 & $100.0 \%$ & 5.5 \\
\hline
\end{tabular}

Pedestrians are prominently at risk of fatality during poor light periods. On the one hand, they are less visible during nighttime. On the other hand, vehicles speed faster as a result of relatively lower traffic volumes at the same time. Accidents under normal weather account for $88.6 \%$ having $90.3 \%$ of fatalities, and its accident severity is even higher comparing with adverse weather. This phenomenon is a little unexpectable and will be discussed later.

\subsection{Victim Characteristics}

During the year of 2015, there were 600 pedestrians killed at mid-blocks, with 10,694 injured. Men comprised $71.7 \%$ of fatalities and $57 \%$ of injuries. Shown in Table 2, victims of these crashes are distributed by several age groups. With regard to numbers, juveniles under 15 have the largest percentage of both total 
Table 2. Victims of accidents at mid-blocks by age (2015).

\begin{tabular}{cccccccc}
\hline \multirow{2}{*}{ Age } & \multicolumn{2}{c}{ Killed } & \multicolumn{2}{c}{ Injured } & \multicolumn{2}{c}{ Total victims } & Percentage killed \\
\cline { 2 - 7 } & Number & Percent & Number & Percent & Number & Percent \\
\hline $0-15$ & 39 & $6.5 \%$ & 3408 & $31.9 \%$ & 3447 & $30.5 \%$ & $1.1 \%$ \\
$16-20$ & 27 & $4.5 \%$ & 837 & $7.8 \%$ & 864 & $7.7 \%$ & $3.1 \%$ \\
$21-25$ & 37 & $6.2 \%$ & 911 & $8.5 \%$ & 948 & $8.4 \%$ & $3.9 \%$ \\
$26-35$ & 61 & $10.2 \%$ & 1462 & $13.7 \%$ & 1523 & $13.5 \%$ & $4.0 \%$ \\
$36-45$ & 107 & $17.8 \%$ & 1137 & $10.6 \%$ & 1244 & $11.0 \%$ & $8.6 \%$ \\
$46-55$ & 93 & $15.5 \%$ & 1039 & $9.7 \%$ & 1132 & $10.0 \%$ & $8.2 \%$ \\
$56-65$ & 81 & $13.5 \%$ & 704 & $6.6 \%$ & 785 & $7.0 \%$ & $10.3 \%$ \\
$66-75$ & 89 & $14.8 \%$ & 565 & $5.3 \%$ & 654 & $5.8 \%$ & $13.6 \%$ \\
Over 75 & 66 & $11.0 \%$ & 631 & $5.9 \%$ & 697 & $6.2 \%$ & $9.5 \%$ \\
Total & 600 & $100.0 \%$ & 10,694 & $100.0 \%$ & 11,294 & $100.0 \%$ & $5.3 \%$ \\
\hline
\end{tabular}

victims and the injured, while their percentage killed (1.1\%) is the lowest. It is obvious that older age groups consist of higher proportion of fatalities. Pedestrians between 36 and 45 share $17.8 \%$ of fatalities, which is the highest among all age groups. The percentage killed of seniors between 66 and 75 is the greatest, reaching $13.6 \%$. Practically $33.4 \%$ of killed pedestrians were over 55 years. It can be concluded that old age groups should be targeted especially in road safety campaigns.

\subsection{Temporal Distribution}

From real traffic accident records, we found that the frequency of accidents varies a lot over time in one day. Figure 2 shows the distributions of vehicle-pedestrian accidents by time of day. Normally, accidents have larger odds of occurrence from 7:00 to 19:00, with two peaks (morning peak and evening peak). Since a great number of people travel during daytime, pedestrians have higher chances of being exposed to vehicles, and the frequency of vehicle-pedestrian accidents rises correspondingly. However, the distribution of fatal ones seems much different. Comparing with daytime, pedestrians have larger odds of being killed in accidents at nighttime. Especially from evening to midnight, the frequency of fatal vehicle-pedestrian accidents is relatively high. This difference may be related to many situations, such as worse visibility, alcohol influences, tiredness after a full-day work, etc. According to above analysis on the temporal distribution, we can conclude that the fatality risk of pedestrians in accidents is higher during dark periods.

\subsection{Basic Model}

To estimate the death probability for pedestrians being hit by a vehicle at mid-blocks, a binary logit model was established. Table 3 shows the calibration 
results suggesting that the statistical fit $(\mathrm{P}=0.0025)$ of the basic model is fairly good, with $\chi^{2}$ statistic $=1468.61$ with 15 degrees of freedom. The Hosmer-Lemeshow statistic is 0.27 ( $>0.05)$, meaning the model seems to fit well. Except for car and pedestrian crossing, most originally selected variables are significant at $5 \%$ level $(\operatorname{Pr}(>|z|)<0.05)$. During model calibrating, variables with confidence level being greater than or equal to $95 \%$ were included in the specification.

Table 3. Results of logistic regression.

\begin{tabular}{|c|c|c|c|c|c|}
\hline Characteristic & Variable & Estimate & $\mathrm{z}$ value & $\operatorname{Pr}(>|z|)$ & Odds ratio \\
\hline & Intercept & -8.34377 & -17.81 & 0.0000 & \\
\hline \multirow{2}{*}{ Weather } & Adverse (control) & - & & & \\
\hline & Normal & 0.68515 & 4.10 & 0.0000 & 1.984 \\
\hline \multirow{2}{*}{ Area type } & Urban (control) & - & & & \\
\hline & Rural & 1.08057 & 9.46 & 0.0000 & 2.946 \\
\hline \multirow{2}{*}{ Road type } & One way (control) & - & & & \\
\hline & Two-way divided & 1.43241 & 5.99 & 0.0000 & 4.189 \\
\hline \multirow{2}{*}{ Pedestrian location } & Roadside (control) & - & & & \\
\hline & Crossing elsewhere & 1.18791 & 9.03 & 0.0000 & 3.280 \\
\hline Speed limit & Speed value $(\mathrm{km} / \mathrm{h})$ & 0.01050 & 4.16 & 0.0000 & \\
\hline \multirow{4}{*}{ Lighting conditions } & Daylight (control) & - & & & \\
\hline & Dark no lighting & 2.17112 & 13.99 & 0.0000 & 8.768 \\
\hline & Dark street lights & 0.94391 & 8.07 & 0.0000 & 2.570 \\
\hline & Dusk or down & 1.52798 & 6.59 & 0.0000 & 4.609 \\
\hline \multirow{3}{*}{ Vehicle type } & Motorcycle (control) & - & & & \\
\hline & Light vehicle & 1.10548 & 3.50 & 0.0005 & 3.021 \\
\hline & Heavy vehicle & 1.63916 & 5.41 & 0.0000 & 5.151 \\
\hline \multirow{2}{*}{ Pedestrian gender } & Female (control) & - & & & \\
\hline & Male & 0.41770 & 3.98 & 0.0001 & 1.518 \\
\hline Pedestrian age & Age value (years) & 0.03180 & 14.65 & 0.0000 & \\
\hline Number of observations & & 11,294 & & & \\
\hline Log likelihood function & & -1610.52 & & & \\
\hline Restricted log likelihood & & -2344.83 & & & \\
\hline Chi squared $\left(\chi^{2}\right)$ & & 1468.61 & & & \\
\hline Degrees of freedom & & 15 & & & \\
\hline $\operatorname{Prob}\left[\chi^{2}>\right.$ critical value $]$ & & 0.0025 & & & \\
\hline Hosmer-Lemeshow test & & 0.27 & & & \\
\hline
\end{tabular}




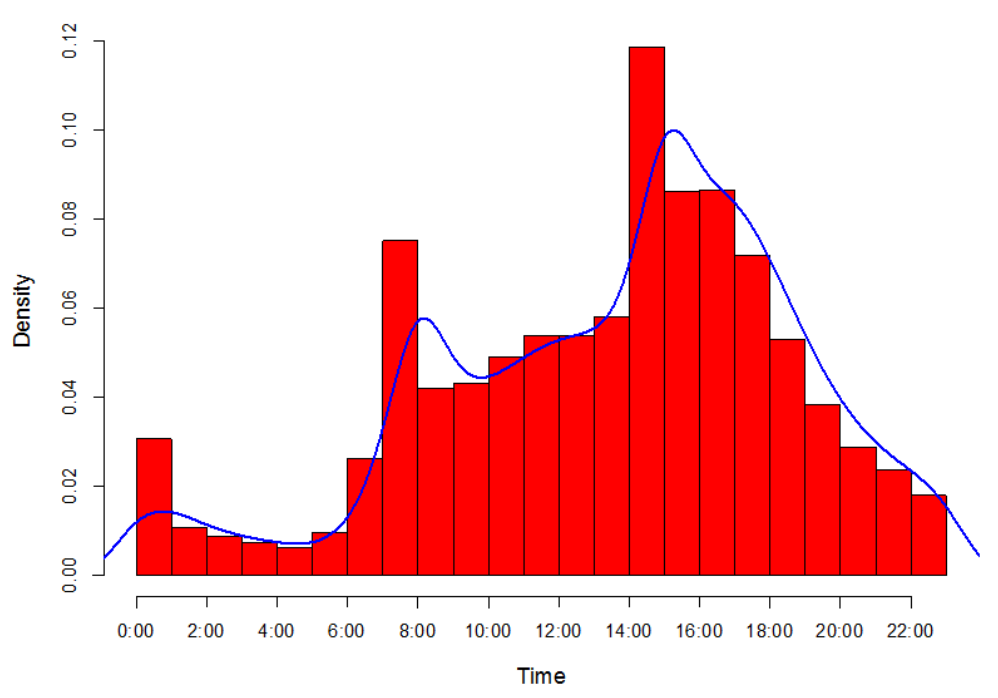

(a) Temporal distribution of total accidents

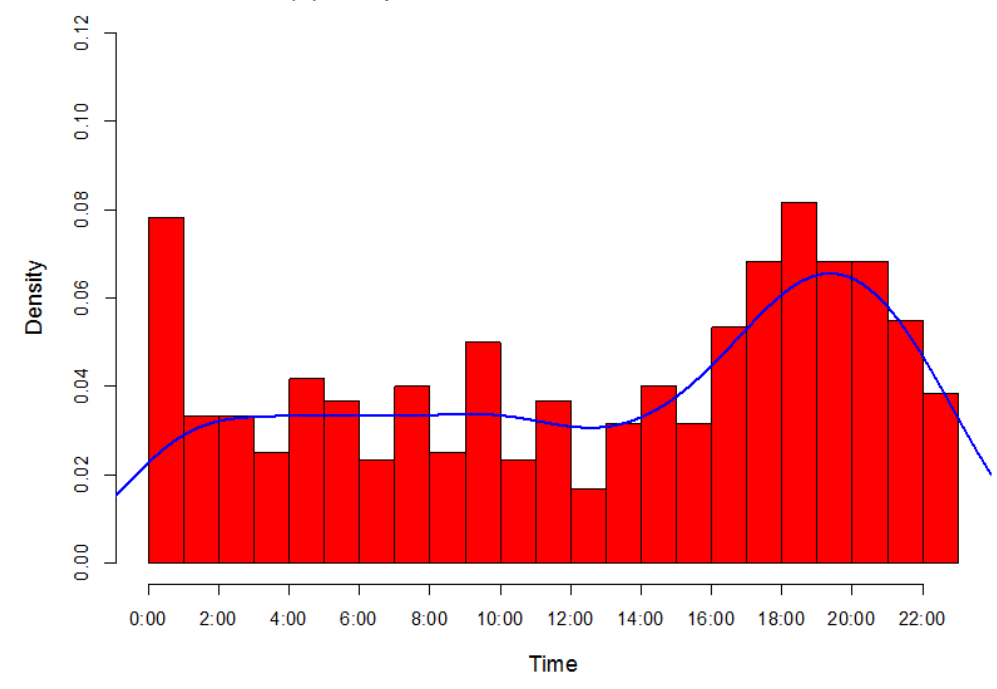

(b) Temporal distribution of fatal accidents

Figure 2. Temporal distribution of vehicle-pedestrian accidents.

As shown in Figure 3, odds ratios were calculated for significant variables. For instance, odds ratio of fatality is 4.19 times higher when pedestrians are moving at mid-blocks on a two-way divided road rather than a one-way road. The greater chances of death on divided roads probably are related to the road width. As divided roads usually have more than two lanes, pedestrians have to spend more time on crossing. Besides, intensive traffic flow also increases the risk of pedestrians getting involved in conflicts with vehicles. Some studies argued that speed is also a potential factor considering the road type, which will be examined separately in this study. In fact, a large number of multi-lane roads in Beijing are divided [37]. Unluckily, due to the detailed information about road lanes is not provided in the data, we use "divided" and "undivided" variables here to stand for multi-lane roads. Based on the analysis above, it is not surprising to find that walking across elsewhere in carriageway is riskier by 3.28 times than walking 


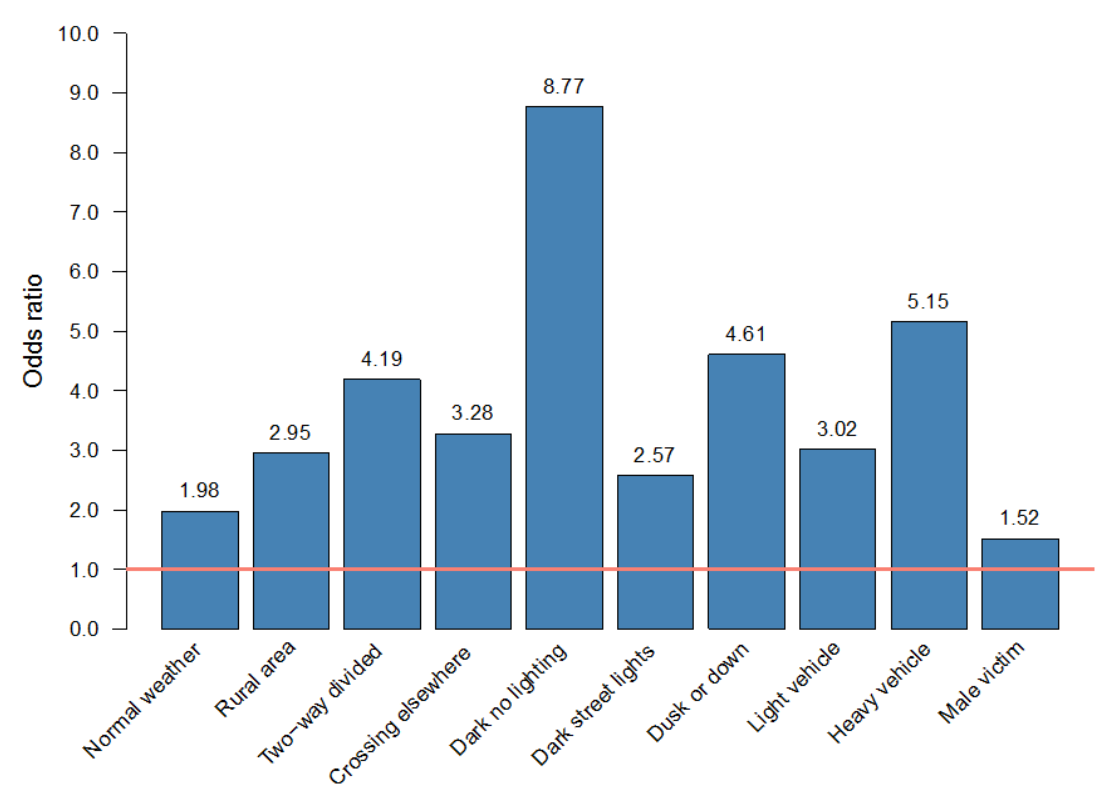

Figure 3. Odds ratios of fatal outcome for different pedestrian accident conditions.

along the roadside; however, the variable of crossing roads using crosswalks is not significant. When pedestrians are going across the carriageway, they have a higher propensity to be at fault [38]. Possibly due to the improper designing, many pedestrians were not enthusiastic about using crossing facilities [39]. Further, many pedestrians risk jaywalking somewhere at the mid-blocks for convenience as the absence of traffic safety awareness.

As expected, the risk of death is 2.95 times higher in rural areas when compared with urban areas. In general, factors affecting accident severity inside and outside urban areas are different [40], e.g. relatively high speed of traffic flow and lacking emergency care at suburban areas. Comparing with motorcycles, the odds of pedestrians being killed are 3.02 times higher when they are hit by a light vehicle, and 5.15 times higher by a heavy vehicle. The weight of vehicles places a major role in how much damage it causes to pedestrians in collisions.

As the model revealed, lighting conditions have the largest influence on the death probability of pedestrians. The odds ratios of fatality are higher by 8.77 times in darkness without street lights, taking daylight condition as the control level. The corresponding odds ratios are 2.57 during dark hours with street lighting, and 4.61 during dusk or dawn conditions. Since speed selection behavior of drivers in reduced visibility changes with their varying driving ability, the vehicle's speed is not always within a safe range, which contributes to the increment in the fatality risk [41].

An interesting finding is that odds of being killed are 1.52 times higher for male victims. This can be presumed that men are taking more dangerous decisions when they are moving at mid-blocks, such as entering the road without proper lookout, running across and so on. Therefore, drivers oftentimes do not have enough time to react, and male pedestrians are more likely hit by a faster vehicle. In addition, alcohol also gives some effect on this issue [42]. However, 
some existing studies found that female pedestrians have a higher death risk and attributed it mostly to the greater vulnerability of females than males [35] [43]. A somewhat surprising result is that normal weather is 1.98 times more risky than adverse weather. Because of the restricted visibility or even slippery roads, not only drivers drive more carefully, but also pedestrian activities are lower under adverse weather conditions [28] [44]. However, there are also some studies indicating that clear weather reduces the probability of fatal injury [26] [36].

\subsection{Model with Interaction Effects}

First-degree interaction terms can be expressed as products of every two variables. As new variables, they were introduced one by one into Equation (2). For those that don't fall within the confidence interval were excluded in the further consideration. Finally, we found three statistically significant interaction terms. After that, the binary logit model described above was re-built incorporating these interaction terms. Table 4 shows the fitting results of the final model, with three interaction terms including (Area type $=$ rural)* $($ Road type $=$ two-way divided), (Area type $=$ rural $)^{\star}($ Pedestrian location $=$ crossing elsewhere), and (Speed limit $)^{\star}($ Pedestrian age). The final model passes significance test $(\mathrm{P}=0.0308)$, with $\chi^{2}$ statistic $=1494.17$ with 20 degrees of freedom. The Hosmer-Lemeshow goodness-of-fit test suggests that the final model also seems to fit well (0.11).

Except for those who have significant interaction terms, odds ratios of main factors in the final model (Table 4) have minor changes by comparing with the basic model. In terms of these cases, we can compare their odds ratios from two ways. For example, Figure 4 shows the interaction between area type and road type, with urban area and one-way road as the reference. Higher risk might seem to be associated with rural area type while it only occurs on one-way roads. Both of two area types are identically dangerous on divided roads, with chances of a fatal outcome being about 6 times higher. It can be concluded that divided roads are less sensitive to area types comparing with one-way roads. In other words, one-way roads on rural areas are more dangerous than those on urban areas.

The interaction between area type and pedestrian location is illustrated in Figure 5, with urban area and roadside as the reference. In general, crossing roads is more hazardous than walking along roads, and rural areas are less safe than urban areas for pedestrian traveling. To be more specific, the probability of death for crossing elsewhere in carriageway is 2.06 times higher than for walking along the roadside at urban areas. This difference is even more pronounced at rural areas. The interaction effect further leads to the odds ratio to be as high as 31.81 for pedestrians not using crosswalks at rural areas. Besides, pedestrians walking on roadsides at rural areas are at higher risk of 6.65 times than at urban areas. This can only be explained by assuming that pedestrians are more likely engaged in risky behaviors at rural areas when they are using roads.

The effect of values of continuous variables on the pedestrian's death risk can be examined through the model Equation (1). For the age of pedestrians, three 
different values are defined. The model relationship between probability of death and road speed limit are shown in Figure 6. Probabilities are calculated presuming the mean value of each residual variable in the equation. It is visible that older pedestrians have a higher death probability across all values of speed limit. Under conditions of identical speed limit, the average death risk is almost 7.21 times higher for a 70-year-old pedestrian, comparing with a 20 -year-old pedestrian. The corresponding odds are about 2.72 times higher for a 45 -year-old pedestrian. It can be attributed to that older pedestrians are less responsive and more vulnerable. This further reflects that senior citizens are not well protected during their traveling. Some existing studies also found that fatality risk rises with pedestrian's age increasing [44] [45].

Table 4. Results of logistic regression with interaction effects.

\begin{tabular}{|c|c|c|c|c|c|}
\hline Characteristic & Variable & Estimate & $\mathrm{z}$ value & $\operatorname{Pr}(>|z|)$ & Odds ratio \\
\hline & Intercept & -8.82731 & -15.25 & 0.0000 & \\
\hline \multirow{2}{*}{ Weather } & Adverse (control) & - & & & \\
\hline & Normal & 0.65983 & 3.95 & 0.0001 & 1.934 \\
\hline \multirow{2}{*}{ Area type } & Urban (control) & - & & & \\
\hline & Rural & 1.28086 & 2.48 & 0.0130 & 3.600 \\
\hline \multirow{2}{*}{ Road type } & One way (control) & - & & & \\
\hline & Two-way divided & - & & & \\
\hline \multirow{2}{*}{ Pedestrian location } & Roadside (control) & 0.72454 & 3.99 & 0.0001 & 2.064 \\
\hline & Crossing elsewhere & 0.02230 & 4.07 & 0.0000 & \\
\hline Speed limit & Speed value $(\mathrm{km} / \mathrm{h})$ & - & & & \\
\hline \multirow{4}{*}{ Lighting conditions } & Daylight (control) & 2.19172 & 13.99 & 0.0000 & 8.951 \\
\hline & Dark no lighting & 0.94375 & 8.05 & 0.0000 & 2.570 \\
\hline & Dark street lights & 1.53297 & 6.59 & 0.0000 & 4.632 \\
\hline & Dusk or down & - & & & \\
\hline \multirow{3}{*}{ Vehicle type } & Motorcycle (control) & 1.04398 & 3.32 & 0.0009 & 2.841 \\
\hline & Light vehicle & 1.57845 & 5.23 & 0.0000 & 4.847 \\
\hline & Heavy vehicle & - & & & \\
\hline \multirow{2}{*}{ Pedestrian gender } & Female (control) & 0.43830 & 4.17 & 0.0000 & 1.550 \\
\hline & Male & 0.04482 & 6.87 & 0.0000 & \\
\hline Pedestrian age & Age value (years) & -8.82731 & -15.25 & 0.0000 & \\
\hline \multirow[t]{3}{*}{ Interaction effects } & $(\text { Rural })^{\star}($ Two-way divided $)$ & -1.36505 & -2.72 & 0.0066 & \\
\hline & $(\text { Rural })^{\star}($ Crossing elsewhere $)$ & 0.84074 & 3.33 & 0.0009 & \\
\hline & $(\text { Speed limit })^{\star}($ Pedestrian age $)$ & -0.00024 & -2.17 & 0.0299 & \\
\hline Number of observations & & 11,294 & & & \\
\hline Log likelihood function & & -1597.74 & & & \\
\hline Restricted log likelihood & & -2344.83 & & & \\
\hline Chi squared $\left(\chi^{2}\right)$ & & 1494.17 & & & \\
\hline Degrees of freedom & & 20 & & & \\
\hline $\operatorname{Prob}\left[\chi^{2}>\right.$ critical value $]$ & & 0.0308 & & & \\
\hline Hosmer-Lemeshow test & & 0.11 & & & \\
\hline
\end{tabular}




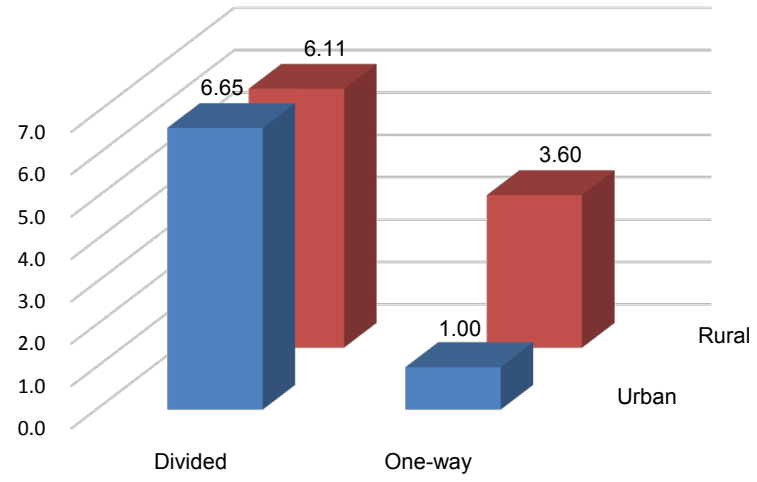

Figure 4. Odds ratio of fatal pedestrian accidents by area type and road type.

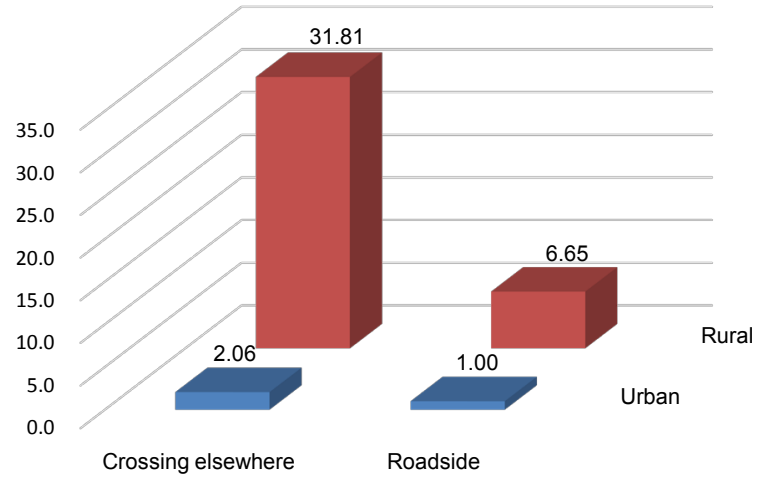

Figure 5. Odds ratio of fatal pedestrian accidents by area type and pedestrian location.

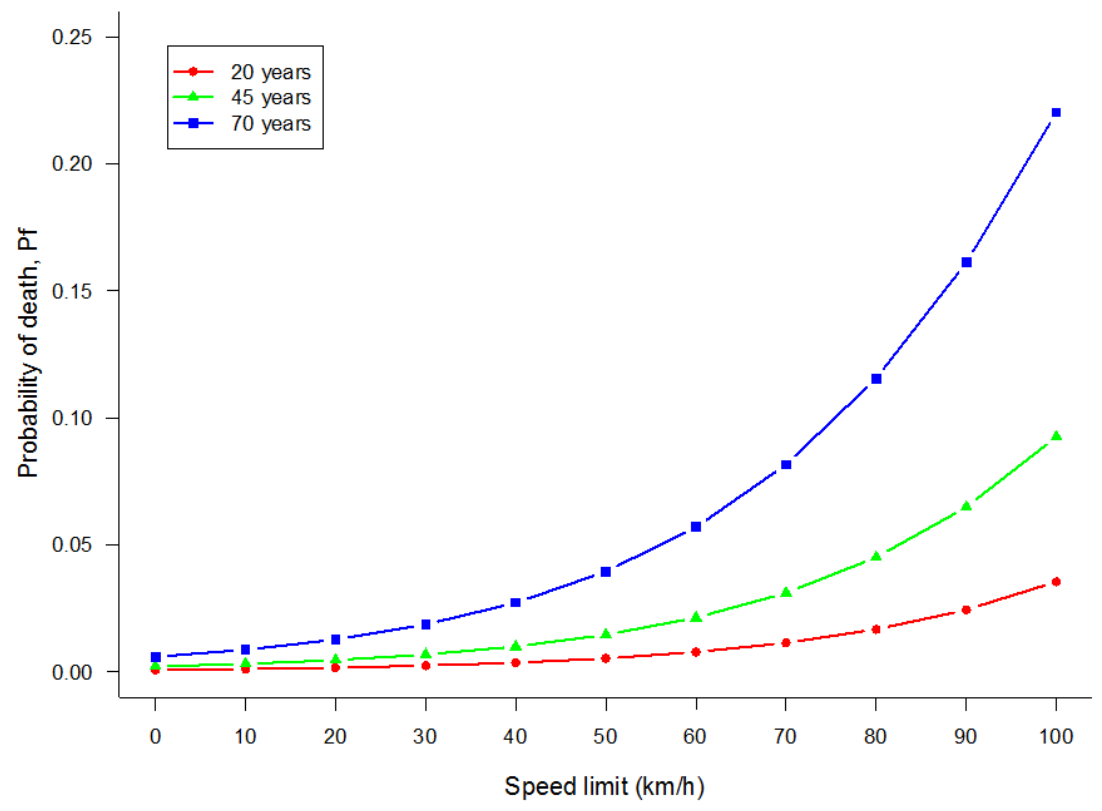

Figure 6. Odds ratio of fatal pedestrian accidents by area type and road type.

However, the actual impact speed of vehicle moving at the accident spot is not available in this dataset. Thus, we can only explain this by supposing that the impact speed may be concerned with the posted road speed limit to some extent. 
Figure 6 also reveals the relationship: when the speed limit increases by 10 $\mathrm{km} / \mathrm{h}$, the fatality risk increases by about $46 \%$. It should be noted that this increasing rate seems relatively small when compared with some existing studies [46] [47]. In this study, the model is actually on the basis of multiplicative effect of different factors. Road speed limit is more likely to be correlated with some other factors, such as area type, road type, etc. Besides, the impact speed, in general, may not be proportional to the posted speed limit. In most cases, drivers slow down when they are approaching the crosswalk and brake hard once the collision is happening soon. As a matter of that, their actual impact speed is below the road's speed limit. With the increment in the speed limit, this difference may be widened correspondingly.

\section{Conclusions}

About $56 \%$ of fatal accidents involving pedestrians in Beijing occurred at mid-blocks. Although the road safety problem in Beijing is improving, pedestrians are still facing the risk of fatality frequently when moving at mid-blocks. Due to the high frequency and fatality risk, investigations into accident characteristics are necessary, and relevant countermeasures should be proposed. Depending on the analysis of real accident data, it can be concluded that regarding accident volumes, the most serious circumstance is related to those undivided roads in urban areas during daytime hours. Nevertheless, the worst death rate of a fatal outcome takes place under the conditions as follows: rural area, divided road, large vehicle, darkness without street lights, and speed limit $\geq 80 \mathrm{~km} / \mathrm{h}$. At the same time, male and older pedestrians have the biggest odds of being killed once involved in a traffic crash.

After analyzing 10,948 vehicle-pedestrian accidents, $5.48 \%$ of pedestrian victims were killed on average. In this study, we used a logistic regression model to identify factors that affect the death risk of pedestrians after being hit. From odds ratios calculated, lighting conditions and the vehicle type are considered as the most significant factors increasing the odds of fatal victims. Chances of death increase 8.77 times in darkness without street lighting. When pedestrians get hit by a heavy vehicle, the death probability is 5.15 times higher than a motorcycle. Another critical factor is speed limit: the calibrated model reveals that there is about $46 \%$ increment in the odds of fatality when the speed limit increases by 10 $\mathrm{km} / \mathrm{h}$. It is egregiously riskier for pedestrians when moving at mid-blocks on a divided road rather than a one-way road: the probability of death is 4.19 times higher for the former. The pedestrian location at mid-blocks also matters: the variable of pedestrians crossing elsewhere in carriageway (not on crosswalks) has the 3.28 times higher odds ratio comparing with those walking along the roadside. Greater odds of death for pedestrians are also related to: normal weather (odds ratio $=1.98)$, rural area $(2.95)$, and male victims (1.52).

In previous research, analyses on the interaction effects of factors in pedestrian accidents were hardly seen after model calibrating. However, correlations 
among different factors are widely existed, and they are important to the final consequences of pedestrian accidents at mid-blocks. In this paper, first-degree interaction effects of factors were considered, and three of them were found: rural area and two-way divided road, rural area and pedestrians crossing elsewhere, as well as speed limit and pedestrian age. Except for some independent risky factors, the analytical method in the study can be applied for identifying some combinations of different factors, which would dramatically increase the fatality risk of pedestrians in accidents.

Some suggestions can be derived from above findings. More attention should be paid into improving the lighting conditions at mid-blocks wherever possible. Relative administrations should strengthen the road management, and pedestrians who cross roads not using crosswalks should be punished accordingly. Moreover, signalization is strongly recommended for those pedestrian crosswalks on divided roads. Furthermore, speed limit reduction measures should be used in non-built-up areas, especially at night. Heavy vehicles, such as buses and trucks, should be equipped with pedestrian detection, which can help reduce the probability and severity of accidents.

A great majority of elderly pedestrians in accidents being killed suggests that the walking environment, traffic facilities and regulations are not suited for the aging society. Consequently, it is indispensable to introduce pedestrian priority at mid-blocks under any conditions. Road safety campaigns are expected to be targeted not only at children but also at senior people crossing or walking along roads during poor visibility periods.

Finally, it is clear that the pedestrian safety level at mid-blocks depends on behaviors of both drivers and pedestrians, as well as whether obeying traffic rules. Road accidents in many cases are man-made, especially for those getting pedestrians involved, yet this study did not go that far for human factors. Therefore, future research is encouraged to focus on observing behaviors of different road users at mid-blocks in order to deeply understand the causation of pedestrian accidents.

\section{Acknowledgements}

This study is a part of the PSRPETE research project, which was funded by the National Key R\&D Program of China (2017YFC0803903).

\section{Conflicts of Interest}

The authors declare no conflicts of interest regarding the publication of this paper.

\section{References}

[1] Kamruzzaman, M., Haque, M.M. and Washington, S. (2014) Analysis of Traffic Injury Severity in Dhaka, Bangladesh. Transportation Research Record: Journal of the Transportation Research Board, 245, 121-130. https://doi.org/10.3141/2451-14 
[2] National Highway Traffic Safety Administration (2016) Traffic Safety Facts. https://crashstats.nhtsa.dot.gov/Api/Public/ViewPublication/812493

[3] European Commission (2017) Annual Accident Report. https://ec.europa.eu/transport/road_safety/sites/roadsafety/files/pdf/statistics/dacot a/asr2017.pdf

[4] Zegeer, C.V. and Bushell, M. (2012) Pedestrian Crash Trends and Potential Countermeasures from Around the World. Accident Analysis and Prevention, 44, 3-11. https://doi.org/10.1016/j.aap.2010.12.007

[5] Verzosa, N. and Miles, R. (2016) Severity of Road Crashes Involving Pedestrians in Metro Manila, Philippines. Accident Analysis and Prevention, 94, 216-226. https://doi.org/10.1016/j.aap.2016.06.006

[6] Traffic Management Bureau of the Public Security Ministry (2014) Statistical Report of Road Traffic Accident.

[7] Lord, D. and Mannering, F. (2010) The Statistical Analysis of Crash-Frequency Data: A Review and Assessment of Methodological Alternatives. Transportation Research Part A: Policy and Practice, 44, 291-305. https://doi.org/10.1016/j.tra.2010.02.001

[8] Pulugurtha, S.S. and Sambhara, V.R. (2011) Pedestrian Crash Estimation Models for Signalized Intersections. Accident Analysis and Prevention, 43, 439-446. https://doi.org/10.1016/j.aap.2010.09.014

[9] Ding, C., Chen, P. and Jiao, J. (2018) Non-Linear Effects of the Built Environment on Automobile-Involved Pedestrian Crash Frequency: A Machine Learning Approach. Accident Analysis and Prevention, 112, 116-126. https://doi.org/10.1016/j.aap.2017.12.026

[10] Lee, J., Abdel-Aty, M. and Shah, I. (2018) Evaluation of Surrogate Measures for Pedestrian Trips at Intersections and Crash Modeling. Accident Analysis and Prevention, in press. https://doi.org/10.1016/j.aap.2018.05.015

[11] Hannah, C., Spasić, I. and Corcoran, P. (2018) A Computational Model of Pedestrian Road Safety: The Long Way Round is the Safe Way Home. Accident Analysis and Prevention, 121, 347-357. https://doi.org/10.1016/j.aap.2018.06.004

[12] Siddiqui, C., Abdel-Aty, M. and Choi, K. (2012) Macroscopic Spatial Analysis of Pedestrian and Bicycle Crashes. Accident Analysis and Prevention, 45, 382-391. https://doi.org/10.1016/j.aap.2011.08.003

[13] Wang, Y. and Kockelman, K.M. (2013) A Poisson-Lognormal Conditional-Autoregressive Model for Multivariate Spatial Analysis of Pedestrian Crash Counts Across Neighborhoods. Accident Analysis and Prevention, 60, 71-84. https://doi.org/10.1016/j.aap.2013.07.030

[14] Amoh-Gyimah, R., Saberi, M. and Sarvi, M. (2016) Macroscopic Modeling of Pedestrian and Bicycle Crashes: Across-Comparison of Estimation Methods. Accident Analysis and Prevention, 93, 147-159. https://doi.org/10.1016/j.aap.2016.05.001

[15] Cai, Q., Lee, J., Eluru, N. and Abdel-Aty, M. (2016) Macro-Level Pedestrian and Bicycle Crash Analysis: Incorporating Spatial Spillover Effects in Dual State Count models. Accident Analysis and Prevention, 93, 14-22. https://doi.org/10.1016/j.aap.2016.04.018

[16] Wang, X., Yang, J., Lee, C., Ji, Z. and You, S. (2016) Macro-Level Safety Analysis of Pedestrian Crashes in Shanghai, China. Accident Analysis and Prevention, 96, 12-21. https://doi.org/10.1016/j.aap.2016.07.028

[17] Medury, A. and Grembek, O. (2016) Dynamic Programming-Based Hot Spot Iden- 
tification Approach for Pedestrian Crashes. Accident Analysis and Prevention, 93, 198-206. https://doi.org/10.1016/j.aap.2016.04.037

[18] Lee, C. and Abdel-Aty, M. (2005) Comprehensive Analysis of Vehicle-Pedestrian crashes at Intersections in Florida. Accident Analysis and Prevention, 37, 775-786. https://doi.org/10.1016/j.aap.2005.03.019

[19] Obeng, K. (2007) Some Determinants of Possible Injuries in Crashes at Signalized Intersections. Journal of Safety Research, 38, 103-112. https://doi.org/10.1016/j.jsr.2006.10.003

[20] Sze, N.N. and Wong, S.C. (2007) Diagnostic Analysis of the Logistic Model for Pedestrian Injury Severity in Traffic Crashes. Accident Analysis and Prevention, 39, 1267-1278. https://doi.org/10.1016/j.aap.2007.03.017

[21] Kong, C. and Yang, J. (2010) Logistic Regression Analysis of Pedestrian Casualty Risk in Passenger Vehicle Collisions in China. Accident Analysis and Prevention, 42, 987-993. https://doi.org/10.1016/j.aap.2009.11.006

[22] Chen, H., Cao, L., and Logan, D. (2012) Analysis of Risk Factors Affecting the Severity of Intersection Crashes by Logistic Regression. Traffic Injury Prevention, 13, 300-307. https://doi.org/10.1080/15389588.2011.653841

[23] Aziz, H.M.A., Ukkusuri, S.V. and Hasan, S. (2013) Exploring the Determinants of Pedestrian-Vehicle Crash Severity in New York City. Accident Analysis and Prevention, 50, 1298-1309. https://doi.org/10.1016/j.aap.2012.09.034

[24] Mohamed, M.G., Saunier, N., Miranda-Moreno, L.F. and Ukkusuri, S.V. (2013) A Clustering Regression Approach: A Comprehensive Injury Severity Analysis of Pedestrian-Vehicle Crashes in New York, US and Montreal, Canada. Safety Science, 54, 27-37. https://doi.org/10.1016/j.ssci.2012.11.001

[25] Sasidharan, L. and Menéndez, M. (2014) Partial Proportional Odds Model-An Alternate Choice for Analyzing Pedestrian Crash Injury Severities. Accident Analysis and Prevention, 72, 330-340. https://doi.org/10.1016/j.aap.2014.07.025

[26] Haleem, K., Alluri, P. and Gan, A. (2015) Analyzing Pedestrian Crash Injury Severity at Signalized and Non-Signalized Locations. Accident Analysis and Prevention, 81, 14-23. https://doi.org/10.1016/j.aap.2015.04.025

[27] Sasidharan, L., Wu, K. and Menendez, M. (2015) Exploring the Application of Latent Class Cluster Analysis for Investigating Pedestrian Crash Injury Severities in Switzerland. Accident Analysis and Prevention, 85, 219-228. https://doi.org/10.1016/j.aap.2015.09.020

[28] Pour-Rouholamin, M. and Zhou, H. (2016) Investigating the Risk Factors Associated with Pedestrian Injury Severity in Illinois. Journal of Safety Research, 57, 9-17. https://doi.org/10.1016/j.jsr.2016.03.004

[29] Ma, Z., Lu, X., Chien, S.I. and Hu, D. (2017) Investigating Factors Influencing Pedestrian Injury Severity at Intersections. Traffic Injury Prevention, 19, 159-164. https://doi.org/10.1080/15389588.2017.1354371

[30] Kim, M., Kho, S. and Kim, D. (2017) Hierarchical Ordered Model for Injury Severity of Pedestrian Crashes in South Korea. Journal of Safety Research, 61, 33-40. https://doi.org/10.1016/j.jsr.2017.02.011

[31] Xie, X., Nikitas, A. and Liu, H. (2018) A Study of Fatal Pedestrian Crashes at Rural Low-Volume Road Intersections in Southwest China. Traffic Injury Prevention, 19, 298-304. https://doi.org/10.1080/15389588.2017.1387654

[32] Salon, D. and McIntyre, A. (2018) Determinants of Pedestrian and Bicyclist Crash Severity by Party at Fault in San Francisco, CA. Accident Analysis and Prevention, 
110, 149-160. https://doi.org/10.1016/j.aap.2017.11.007

[33] Olszewski, P., Szagała, P., Wolański, M. and Zielińska, A. (2015) Pedestrian Fatality Risk in Accidents at Unsignalized Zebra Crosswalks in Poland. Accident Analysis and Prevention, 84, 83-91. https://doi.org/10.1016/j.aap.2015.08.008

[34] Zahabi, S.A.H., Strauss, J., Manaugh, K. and Miranda-Moreno, L.F. (2011) Estimating Potential Effect of Speed Limits, Built Environment, and Other Factors on Severity of Pedestrian and Cyclist Injuries in Crashes. Transportation Research Record: Journal of the Transportation Research Board, 2247, 81-90. https://doi.org/10.3141/2247-10

[35] Islam, S. and Jones, S.L. (2014) Pedestrian At-Fault Crashes on Rural and Urban Roadways in Alabama. Accident Analysis and Prevention, 72, 267-276. https://doi.org/10.1016/j.aap.2014.07.003

[36] Eluru, N., Bhat, C.R. and Hensher, D.A. (2008) A Mixed Generalized Ordered Response Model for Examining Pedestrian and Bicyclist Injury Severity Level in Traffic Crashes. Accident Analysis and Prevention, 40, 1033-1054. https://doi.org/10.1016/j.aap.2007.11.010

[37] Martin, J. and Wu, D. (2017) Pedestrian Fatality and Impact Speed Squared: Cloglog Modeling from French National Data. Traffic Injury Prevention, 19, 94-101. https://doi.org/10.1080/15389588.2017.1332408

[38] Theofilatos, A., Graham, D. and Yannis, G. (2012) Factors Affecting Accident Severity Inside and Outside Urban Areas in Greece. Traffic Injury Prevention, 13, 458-467. https://doi.org/10.1080/15389588.2012.661110

[39] Ulfarsson, G.F., Kim, S. and Booth, K.M. (2010) Analyzing Fault in Pedestrian-Motor Vehicle Crashes in North Carolina. Accident Analysis and Prevention, 42, 1805-1813. https://doi.org/10.1016/j.aap.2010.05.001

[40] Al-Shammari, N., Bendak, S. and Al-Gadhi, S. (2009) In-Depth Analysis of Pedestrian Crashes in Riyadh. Traffic Injury Prevention, 10, 552-559. https://doi.org/10.1080/15389580903175313

[41] Zhang, W., Hu, Z., Feng, Z., Ma, C., Wang, K. and Zhang, X. (2018) Investigating Factors Influencing Drivers' Speed Selection Behavior under Reduced Visibility Conditions. Traffic Injury Prevention, 19, 488-494. https://doi.org/10.1080/15389588.2018.1453134

[42] Eichelberger, A.H., McCartt, A.T. and Cicchino, J.B. (2018) Fatally Injured Pedestrians and Bicyclists in the United States with High Blood Alcohol Concentrations. Journal of Safety Research, 65, 1-9. https://doi.org/10.1016/j.jsr.2018.02.004

[43] Ulfarsson, G.F. and Mannering, F.L. (2004) Differences in Male and Female Injury Severities in Sport-Utility Vehicle, Minivan, Pickup and Passenger Car Accidents. Accident Analysis and Prevention, 36, 135-147. https://doi.org/10.1016/S0001-4575(02)00135-5

[44] Kim, J., Ulfasson, G.F., Shankar, V.N. and Kim, S. (2008) Age and Pedestrian Injury Severity in Motor-Vehicle Crashes: A Heteroskedastic Logit Analysis. Accident Analysis and Prevention, 40, 1695-1702. https://doi.org/10.1016/j.aap.2008.06.005

[45] O’Hern, S., Oxley, J. and Logan, D. (2015) Older Adults at Increased Risk as Pedestrians in Victoria, Australia: An Examination of Crash Characteristics and Injury Outcomes. Traffic Injury Prevention, 16, S161-S167.

[46] Rosén, E., Stigson, H. and Sander, U. (2011) Literature Review of Pedestrian Fatality Risk as a Function of Car Impact Speed. Accident Analysis and Prevention, 43, 25-33. https://doi.org/10.1016/j.aap.2010.04.003 
[47] Oikawa, S., Matsui, Y., Doi, T. and Sakurai, T. (2016) Relation between Vehicle Travel Velocity and Pedestrian Injury Risk in Different Age Groups for the Design of a Pedestrian Detection System. Safety Science, 82, 361-367.

https://doi.org/10.1016/j.ssci.2015.10.003 